trast to several other historians, he stresses the experimental basis, origins and methods of Ampère's electrodynamics. $\mathrm{He}$ argues that "Ampère's experimentation [in electro-dynamics] was almost always guided by predetermined goals; his initial agenda was to specify a mathematical expression for a phenomenological force law and to determine the circuits followed by the electric currents he believed existed within magnets".

Hofmann also points out that Ampère did not seek quantitative precision nor, unlike Faraday, did he seek experimental novelties. Rather, he preferred deductive analysis and confirming experimentation to inductive generalizations. He believed that his electrodynamics had originated in the same way as, and paralleled in its argumentative form, Newton's gravitational theory.

Here, as throughout his study, Hofmann devotes much analysis to Ampère's philosophy of science and metaphysics, in particular elucidating his overall research programme and assessing the means by and extent to which he achieved it.

After the publication in 1826-27 of his essay on the theory of electrodynamic phenomena, Ampère ceased work in this field. His research during the final decade of his life was anticlimactic: he again occupied himself with the unfruitful pursuit of problems of classification.

Although he was elected in 1824 to the Collège de France (as the experimental, not the theoretical, professor of physics), he continued to remain an outsider to the scientific community. His lack of training, his temperament and his fervent yet unrequited pursuit of metaphysics had turned him, as Hofmann shows, into a scientist-philosopher suigeneris.

David Cahan is in the Department of History, University of Nebraska-Lincoln, 612 Oldfather, PO Box 880327, Lincoln, Nebraska 68588-0327, USA.

\section{The framework of feelings}

The Emotional Brain: The Mysterious Underpinnings of Emotional Life by Joseph LeDoux

Simon \& Schuster: 1996. Pp. 384. \$25

\section{Raymond J.Dolan}

The progress of cognitive neuroscience towards an understanding of mind is beyond question, but one component has so far proved intractable - emotion. With few notable exceptions, the preferred strategy of cognitive neuroscience in dealing with emotion has been to ignore it. Given that so much of everyday experience is shaped by emotion, it is difficult to understand how any concept of mind devoid of emotion can be taken seriously.

The Emotional Brain by Joseph LeDoux represents an important step in bringing emotion back into mainstream cognitive neuroscience. It follows a notable work by Antonio Damasio, Descartes' Error (published by Grosset/Putnam). Both can be viewed as part of a process of rehabilitation for cognitive neuroscience from a longstanding state of emotional denial.

Whereas Damasio attempted to provide a comprehensive theory of emotion, LeDoux focuses on fear. This is justified by reference to the fact that fear represents a class of emotion that is conserved across species, so neurobiological data from other species can provide important clues about the probable organization of fear in the human brain. This focus also avoids the cul-de-sac that characterizes debate within psychology about what constitutes an emotion and whether there are fundamental emotions.

The account of emotion emphasized here is unashamedly neurobiological. Its historical antecedents are the anatomical and physiological theories of James Papez, Paul MacLean and Donald Hebb. These approaches were limited by an attempt to account for all emotions in terms of the function of a single brain system.

As Leslie Brothers has pointed out, this had the unfortunate consequence of a reification of emotion in the concept of the limbic system, a concept now viewed as fundamentally flawed. LeDoux takes the position that there is no such thing as a single, allinclusive emotion faculty, but that there are distinct systems that mediate particular emotions.

LeDoux's contribution to the understanding of fear has been considerable. His work is exemplary in bridging anatomical localization and neurobiological mechanisms of emotion. LeDoux and colleagues have shown that a critical mammalian system for responding to fear involves the thalamus and amygdala. Critical processing related to fear takes place in the amygdala, whose outputs can be functionally and anatomically separated into different components of a fear response, for example autonomic responses.

Emotional disturbances represent the commonest form of human psychopathology. The social, cognitive or pharmacological mechanisms of these disturbances have been emphasized in research efforts over the past 30 years. Much of this work is speculative, in that it lacks a plausible, anatomically grounded, neurobiological account of emotion.

The pathological counterparts of fear include anxiety, phobias and post-traumatic stress disorder, and LeDoux proposes that aberrant activation of a fear system is likely to be fundamentally important in these areas. The goal of psychopathological research must be to provide models for such aberrant activation. In other words, how does processing that supports acquired fear gain access to systems mediating innate fear responses?

An obstacle to understanding emotion has been the issue of the centrality of conscious emotion. LeDoux points out that an absence of awareness is the rule for much of mental life. He assumes that in animals with a capacity for conscious awareness, emotional feelings will be present, although this is not central to understanding emotion.

This concept has much in common with Jerry Fodor's notion of modular systems, whose activity is assumed to be automatic, obligatory and cognitively impenetrable. In this framework, it is the outputs of emotionally specific modular systems that are available as experienced feelings. Provocatively, he concludes that conscious feelings are at best red herrings in the pursuit of an understanding of emotion. However, by the same token, so also are other outputs from a fear-processing system, including autonomic and other behavioural responses.

This view of emotion is clearly distinct from William James' notion of fear as the perception of physical responses; both feelings of fear and its autonomic concomitants are effects of activity within a system specialized for the detection of danger, and the system that detects fear constitutes what is fundamental.

Psychology makes a clear distinction between cognition and emotion, and LeDoux implicitly subscribes to this dichotomy. The critical issue here is the absence of any unanimity about the definition of cognitive. If cognition refers to systems that embody a transformation of inputs, then emotion can also be construed as cognitive. In this framework, what distinguishes emotion from other modes of cognition is the evaluative nature of these transformations.

What is most gratifying in this book is that, for once, the neurobiological mechanisms of emotion are put centre-stage. Generous reference is made to other modes of enquiry wherever this illuminates the author's general thesis. The style of writing is highly accessible, and LeDoux's musical and literary references reveal a man clearly in touch with his own emotional feelings. All said, The Emotional Brain is a stimulating and thoughtful work and is essential reading for any serious student of human emotion.

Raymond J. Dolan is in the Wellcome

Department of Cognitive Neurology, Institute of Neurology, Queen Square, London WC1N 3BG, $U K$. 